\title{
Reduction of Line Losses and Enhancement of Voltage Stability in a Radial Distribution System with Renewable Distributed Generation
}

\author{
Martha Mbenge Kyule \\ Department of Electrical and Information Engineering \\ The University of Nairobi \\ Nairobi, Kenya
}

\author{
Moses Peter Musau \\ Department of Electrical and Information Engineering \\ The University of Nairobi \\ Nairobi, Kenya
}

\author{
Nicodemus Odero Abungu \\ Department of Electrical and Electronic Engineering \\ Machakos University \\ Machakos, Kenya
}

\begin{abstract}
Reduction of line losses in a distribution system is very important and cannot be overlooked in the modern distribution systems which have been expanded to meet the increased load demand. This is because line losses have an undesirable effect on the voltage profile of the power system especially when electrical power has to be transmitted over long distances due to increased line resistance. Consequently this results to increased voltage drop along the lines and voltage compensation has to be employed to avoid voltage collapse. Introduction of Renewable Distributed Generation (RDG) in the distribution network has been deployed in addressing this problem in the recent past. However, interconnection of these RDGs to the grid has to be properly done to enhance the performance of the system by reducing line losses and improving the system's voltage profile. A formulation of the multi-objective problem of reducing line losses and enhancing voltage stability of the distribution system with RDGs is very important for proper system operation. This paper presents a three method approach of optimally locating and sizing RDGs using Voltage Stability Index (VSI), Adaptive Genetic Algorithm (AGA) and Simulated annealing (SA) to solve this problem. Researchers have solved this problem by; using under frequency load shedding, optimally locating Flexible AC Transmission systems (FACTS) and by use of capacitor banks to achieve reactive power compensation. Over the last decade optimal DG placement and sizing has been an emergent trend. This paper contains a review of the methods applied by other researchers in solving the problem, a detailed formulation of the multi-objective problem and an analysis of the solutions obtained from the standard IEEE 33 Bus test system using MATLAB. Results from the proposed method are compared with Particle Swarm Optimization (PSO) method and Optimal Power Flow and Improved Harmony Search (OPF and IHS) hybrid. Obtained results indicate that properly located and sized RDGs reduce line losses and increase voltage stability in a radial distribution network.
\end{abstract}

Keywords:-Renewable Distributed Generation (RDG), Voltage Stability Index (VSI), Adaptive Genetic Algorithm (AGA), Simulated Annealing (SA).

\section{INTRODUCTION}

Owing to the increase in electrical load at the distribution level of a power system, distribution network expansion has proofed to be inevitable. It is therefore, critical to ensure that the system remains stable and reliable. Renewable Distributed Generation has been an emerging trend in curbing the problem of line losses and voltage stability in expansive distribution networks by having RDGs located near the consumer centers. This reduces transmission line losses and eliminates the cost of transmission network expansion that would be required to cater for the additional electrical load. RDGs have been adopted because they pose minimal environmental effects and cannot be depleted unlike fossil fuel Distributed Generators. Following the increased advocacy on environmental conservation worldwide, RDG has become an active emergent trend over the last decade.

Contribution:-This research paper gives a review of various methods used in placing and sizing grid interconnected DGs, a detailed formulation of the multi-objective problem aimed at reducing line losses and improving voltage stability of a radial distribution system with Renewable Distributed Generation and a two method hybrid optimization technique of solving this problem using a proper blend of wind and Photovoltaic solar sources.

Paper organization:-This paper has five major parts; part II contains literature review, Part III has the problem formulation, part IV consists of the methodology, part V contains the results and a detailed analysis and part VI is made up of the conclusion.

\section{LITERATURE REVIEW}

Renewable distributed Generation refers to renewable energy sources that are located at load centers either individually or with grid integration so as to meet increased electrical load. Grid Interconnected Renewable Distributed Generation is an emerging trend in modern power systems and it is therefore important to study their effects in the distribution system and also how to improve system performance. Previous research works have found out that incorporation of RDGs in to the grid may affect the system's power factor, line losses and voltage profile due to the fluctuation of power output from the sources. Consequently, system protection may be affected because RDGs may cause reverse active power flow in the feeders [1] [2]. Non-optimally sized and located RDGs results in increased losses, costs and system instability. 
Researchers have used bus stability indices to determine the lines that are susceptible to voltage instability. These include Voltage Stability Index (VSI) [3] [4]. This paper contains a three method approach of solving the multi-objective problem of reducing line losses and total voltage deviation of a radial distribution system on the IEEE 33 Bus system.

\section{PROBLEM FORMULATION}

The following single objectives were formulated and later combined into the multi-objective function.

\section{A. Total line losses, $\mathbf{J}_{\text {TLL }}$.}

Equation 1 is used to calculate the base values without any RDG penetration into the grid.

$$
\mathrm{J}_{\mathrm{TLL}}=\sum_{\mathrm{i}=1}^{\mathrm{N}}\left(\mathrm{R}_{\mathrm{k}}\right) \frac{\left(\mathrm{P}_{\mathrm{k}}\right)^{2}+\left(\mathrm{Q}_{\mathrm{k}}\right)^{2}}{\left|\mathrm{~V}_{\mathrm{k}}\right|^{2}}
$$

Where $\mathrm{i}=1,2,3, \ldots, \mathrm{N}$ buses, $\mathrm{R}_{\mathrm{k}}$ and $\mathrm{X}_{\mathrm{k}}$ are resistance and reactance of the kth branch respectively, $P_{k}$ and $Q_{k}$ are the real and reactive power at the sending end of the kth branch, $\mathrm{P}_{\mathrm{kDG}}$ and $Q_{\mathrm{kDG}}$ are the real and reactive powers of the RDGs connected to the sending end of the kth branch and $\left|V_{k}\right|$ is the magnitude of the voltage at the sending end of the kth branch.

\section{B. Total voltage deviation, $J_{T V D}$.}

$\mathrm{J}_{\mathrm{TVD}}=\sum_{\mathrm{i}=1}^{\mathrm{N}}\left|1-\mathrm{V}_{\mathrm{i}}\right|$

Where $i=1,2,3 \ldots, N$ buses and $V_{i}$ is per unit voltage at each bus.

C. Multi-objective function, MOF.

$\mathrm{MOF}=\mathrm{W} 1 \mathrm{~J}_{\mathrm{TLL}}+\mathrm{W} 2 \mathrm{~J}_{\mathrm{TVD}}$

D. Constraints.

(i) Bus voltage limits should be maintained within the acceptable levels

$$
0.95 \text { p.u } \leq V_{i} \leq 1.05 \text { p.u }
$$

(ii) RDG capacity constraints

$$
\begin{aligned}
& P_{D G \text { min }} \leq P_{D G} \leq P_{D G \text { max }} \\
& Q_{D G \text { min }} \leq Q_{D G} \leq Q_{D G \text { max }}
\end{aligned}
$$

Where $P_{D G \text { min }}$ and $P_{D G \text { max }}$ are the minimum and maximum active power limits and $Q_{D G \min }$ and $\mathrm{Q}_{\mathrm{DG} \text { max }}$ are the minimum and maximum reactive power limits respectively.

(iii) Power flow constraints

$\mathrm{P}_{\mathrm{Gi}}-\mathrm{P}_{\mathrm{Di}}=\sum_{\mathrm{k}=1}^{\mathrm{N}} \mathrm{V}_{\mathrm{i}} \mathrm{V}_{\mathrm{k}}\left\{\mathrm{G}_{\mathrm{ik}} \cos \left(\delta_{\mathrm{i}}-\delta_{\mathrm{k}}\right)+\right.$

$\left.\mathrm{B}_{\mathrm{ik}} \sin \left(\delta_{\mathrm{i}}-\delta_{\mathrm{k}}\right)\right\}$

$\mathrm{Q}_{\mathrm{Gi}}-\mathrm{Q}_{\mathrm{Di}}=\sum_{\mathrm{k}=1}^{\mathrm{N}} \mathrm{V}_{\mathrm{i}} \mathrm{V}_{\mathrm{k}}\left\{\mathrm{G}_{\mathrm{ik}} \sin \left(\delta_{\mathrm{i}}-\delta_{\mathrm{k}}\right)-\right.$

$\left.\mathrm{B}_{\mathrm{ik}} \cos \left(\delta_{\mathrm{i}}-\delta_{\mathrm{k}}\right)\right\}$

Where $\mathrm{P}_{\mathrm{Gi}}-\mathrm{P}_{\mathrm{Di}}$ gives the real power injected and $\mathrm{Q}_{\mathrm{Gi}}-\mathrm{Q}_{\mathrm{Di}}$ is the reactive power injected at a bus, $G_{i k}$ and $B_{i k}$ are the conductance and susceptance of the line between buses $\mathrm{i}$ and $\mathrm{k}$.

$$
\begin{aligned}
& \text { E. Voltage Stability Index formulation [5]. } \\
& \operatorname{VSI}(j)=V_{i}^{4}-4 V_{i}^{2}\left(P_{L j} R_{i j}+Q_{L j} X_{i j}\right)-4\left(P_{L j} X_{i j}-\right. \\
& \left.Q_{L j} R_{i j}\right)^{2}
\end{aligned}
$$

Where $\operatorname{VSI}(j)$, is the voltage stability index of the receiving end bus, $V_{i}$ is the magnitude of the sending-end voltage, $R_{i j}$ and $X_{i j}$ represent the line resistance and line reactance respectively. $P_{i j}$ and $Q_{i j}$ are the real and reactive power loads connected to the jth bus.

The voltage of all buses and currents at all the branches can be determined from load flow studies. Consequently, $P_{i j}$ and $P Q_{i j}$ at the receiving end of each line can be calculated. Thus bus with the minimum VSI is more proximate to voltage collapse [6] [5].

\section{METHODOLOGY}

The following is the process undertaken during the three method optimization technique.

Step 1: The IEEE 33 Bus system data was obtained.

Step 2: Candidate buses were determined using the VSI.

Step 3: The buses with the least VSI were taken as the candidate buses for RDG placement. RDG sizes were determined using Adaptive Genetic Algorithm ad Simulated Annealing (AGA-SA). The candidate bus with the results that greatly enhance system performance is selected as the first RDG location and size.

Step 4: Determine the second RDG size for the remaining candidate buses with the bus data updated with the first RDG size using Adaptive Genetic Algorithm and Simulated Annealing.

Step 5: Determine the third RDG size for the remaining candidate buses with bus data updated with the first and second RDG sizes using Adaptive Genetic Algorithm and Simulated Annealing.

Step 6: Steps 3, 4 and 5 were carried out for Photo voltaic Solar generators (generates real power only) and wind generators (generates both real and reactive power) separately.

Step 6: Results were tabulated and analyzed. They were compared with other research works.

Tables 1 and 2 show the mapping of the Adaptive Genetic Algorithm and Simulated Annealing parameters used in the optimization.

Table 1. Parameter mapping in Adaptive Genetic Algorithm

\begin{tabular}{|l|c|}
\hline Parameter & Value \\
\hline Initial population & 100 \\
\hline $\begin{array}{l}\text { Mutation probability } \\
\text { (M) }\end{array}$ & $\begin{array}{c}\text { Was adapted to vary as shown; } \\
M_{0}=0.01\end{array}$ \\
& $M=M_{0}+\left(\frac{k}{\text { Iter }_{\text {max }}}\right) * M_{0}$ \\
\hline $\begin{array}{l}\text { Cross-over probability } \\
\text { (c) }\end{array}$ & 0.85 \\
\hline Maximum iterations & $\left(\right.$ Iter $\left._{\max }\right)=10$ \\
\hline
\end{tabular}


Table 2. Parameter mapping in Simulated Annealing Algorithm

\begin{tabular}{|l|l|c|}
\hline Parameter & Meaning & Value \\
\hline Initial population & $\begin{array}{l}\text { Initial particle size after 10 } \\
\text { iterations }\end{array}$ & 5 \\
\hline Particle & Possible solution & 5 \\
\hline Initial temperature & $\begin{array}{l}\text { Initial DG size obtained from } \\
\text { AGA }\end{array}$ & 0.95 \\
\hline Cooling coefficient $(\alpha)$ & \multicolumn{1}{|c}{$0<\alpha<1$} & 0.95 \\
\hline $\begin{array}{l}\text { Maximum iterations } \\
(\text { Iter }\end{array}$ & Maxim $)$ & 50 \\
\hline Final temperature & Optimal DG size & \\
\hline
\end{tabular}

\section{RESULTS AND ANALYSIS}

The Proposed method was tested on IEEE 33 bus system with base active power load of $3.72 \mathrm{MW}$ and base reactive power load of 2.3 MVAR. W1 was set to be equal to W2 of the multiobjective function to ensure that the solution met both objectives simultaneously. The P.F was set at 0.83 based on the setting of the work to be compared with by K. Varesi [2]

Table 3 shows the base values of JTLL and JTVD before RDG integration into the system.

Table 3. Base JTLL and JTVD

\begin{tabular}{|l|c|c|c|}
\hline System & $\begin{array}{l}\text { Real JTLL } \\
\text { (KW) }\end{array}$ & $\begin{array}{l}\text { Reactive JTLL } \\
\text { (KVAR) }\end{array}$ & JTVD \\
\hline $\begin{array}{l}\text { IEEE 33 } \\
\text { bus system }\end{array}$ & 219.2 & 148.6 & 0.1593 \\
\hline
\end{tabular}

Figure 1 shows Voltage stability indices for each bus based on equation 9 using Newton Raphson method.

Figure 1. Voltage stability index for IEEE 33 Bus system

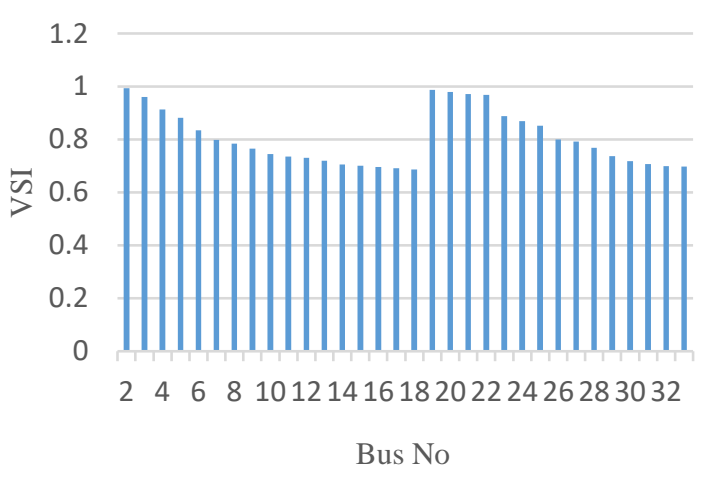

The weakest buses with VSI of less than or equal to 0.7 were identified as buses $18,17,16,32$ and 33 with voltage stability indices of $0.6864,0.6905,0.6958,0.6986$ and 0.6971 respectively.

Table 4 shows the optimal RDG size, the total line losses and total voltage deviation after incorporating one real power generating RDG.
Table 4: Results with placement of one RDG generating real power only

\begin{tabular}{|c|c|c|c|c|c|c|}
\hline & & & \multirow{3}{*}{$\begin{array}{l}\text { JTLL } \\
\text { (KW) }\end{array}$} & \multirow{3}{*}{ JTVD } & & \\
\hline \multirow{2}{*}{ Method } & \multirow{2}{*}{$\begin{array}{l}\text { Bus } \\
\text { No. }\end{array}$} & \multirow{2}{*}{$\begin{array}{c}\text { RDG } \\
\text { SIZE } \\
\text { P } \\
(\mathbf{M W})\end{array}$} & & & \multirow{2}{*}{$\begin{array}{c}\% \\
\Delta \mathbf{J T L L}\end{array}$} & \multirow{2}{*}{$\begin{array}{c}\% \\
\Delta \mathbf{J T V} \\
\text { D }\end{array}$} \\
\hline & & & & & & \\
\hline PSO [2] & 6 & 2.59 & 112 & $\begin{array}{c}\text { Not } \\
\text { considered }\end{array}$ & $47 \%$ & \\
\hline $\begin{array}{l}\text { OPF and } \\
\text { IHS [12] }\end{array}$ & 6 & 2.59 & 111.1 & $\begin{array}{c}\text { Not } \\
\text { considered }\end{array}$ & $47 \%$ & \\
\hline $\begin{array}{l}\text { VSI, } \\
\text { AGA } \\
\text { and SA }\end{array}$ & 33 & $\begin{array}{c}3.563 \\
5 \\
\end{array}$ & 82.4 & 0.0608 & $62.4 \%$ & $61.8 \%$ \\
\hline
\end{tabular}

The proposed method gives a $62.4 \%$ reduction on the total line losses which is greater compared to the losses from the other comparative works. It also gives a $61.8 \%$ reduction in the total voltage deviation and the system performance is therefore, enhanced by having a 3.56 MW Photovoltaic Solar generator placed at bus 33 .

Table 5 shows the optimal RDG sizes, the total line losses and total voltage deviation after incorporating two real power generating RDGs.

Table 5: Results with placement of two RDGs generating real power only

\begin{tabular}{|c|c|c|c|c|c|c|}
\hline \multirow{2}{*}{ Method } & \multirow{2}{*}{$\begin{array}{l}\text { Bus } \\
\text { No. }\end{array}$} & $\begin{array}{l}\text { RDG } \\
\text { SIZE }\end{array}$ & \multirow{2}{*}{$\begin{array}{l}\text { JTLL } \\
\text { (KW) }\end{array}$} & \multirow[t]{2}{*}{ JTVD } & \multirow{2}{*}{$\begin{array}{c}\% \\
\Delta \mathbf{J T L L}\end{array}$} & \multirow{2}{*}{$\begin{array}{c}\% \\
\Delta \text { JTVD }\end{array}$} \\
\hline & & $\begin{array}{c}\mathbf{P} \\
\text { (MW) }\end{array}$ & & & & \\
\hline \multirow{2}{*}{ PSO [2] } & 6 & 2.59 & \multirow{2}{*}{96.1} & \multirow{2}{*}{$\begin{array}{c}\text { Not } \\
\text { considered }\end{array}$} & \multirow{2}{*}{$54 \%$} & \\
\hline & 15 & 0.473 & & & & \\
\hline \multirow{2}{*}{$\begin{array}{l}\text { OPF and } \\
\text { IHS [12] }\end{array}$} & 13 & 0.85 & \multirow{2}{*}{87.16} & \multirow{2}{*}{$\begin{array}{c}\text { Not } \\
\text { considered }\end{array}$} & \multirow{2}{*}{$59 \%$} & \\
\hline & 30 & 1.15 & & & & \\
\hline \multirow{2}{*}{$\begin{array}{l}\text { VSI, } \\
\text { AGA } \\
\text { and SA }\end{array}$} & 33 & 3.5635 & \multirow{2}{*}{82.9} & \multirow{2}{*}{0.0427} & \multirow{2}{*}{$62.1 \%$} & \multirow{2}{*}{$73.2 \%$} \\
\hline & 18 & 0.5434 & & & & \\
\hline
\end{tabular}

The proposed method gives a $62.1 \%$ reduction in total line losses with incorporation of two real power generating RDGs at buses 33 and 18 . There was $73.2 \%$ improvement in the total voltage deviation from the base value with two real power generating RDGs incorporated as compared to the $61.8 \%$ improvement with only one real power generating RDG.

Table 6 shows the optimal RDG sizes, the total line losses and total voltage deviation after incorporating three real power generating RDGs.

Table 6: Results with placement of three RDGs generating real power only

\begin{tabular}{|c|c|c|c|c|c|c|}
\hline \multirow{2}{*}{ Method } & \multirow{2}{*}{$\begin{array}{l}\text { Bus } \\
\text { No. }\end{array}$} & $\begin{array}{l}\text { RDG } \\
\text { SIZE }\end{array}$ & \multirow{2}{*}{$\begin{array}{l}\text { JTLL } \\
\text { (KW) }\end{array}$} & \multirow{2}{*}{ JTVD } & \multirow{2}{*}{$\begin{array}{c}\% \\
\Delta \mathbf{J T L} \\
\mathbf{L}\end{array}$} & \multirow{2}{*}{$\begin{array}{c}\% \\
\Delta \text { JTVD }\end{array}$} \\
\hline & & $\begin{array}{c}\mathbf{P} \\
(\mathbf{M W})\end{array}$ & & & & \\
\hline \multirow{3}{*}{ PSO [2] } & 6 & 2.59 & \multirow{3}{*}{88.6} & \multirow{3}{*}{$\begin{array}{c}\text { Not } \\
\text { considered }\end{array}$} & \multirow{3}{*}{$58 \%$} & \\
\hline & 15 & 0.473 & & & & \\
\hline & 25 & 0.637 & & & & \\
\hline
\end{tabular}




\begin{tabular}{|l|c|c|c|c|c|c|}
\hline \multirow{3}{*}{$\begin{array}{l}\text { OPF and } \\
\text { IHS [12] }\end{array}$} & 13 & 0.8 & \multirow{4}{*}{72.8} & $\begin{array}{c}\text { Not } \\
\text { considered }\end{array}$ & $66 \%$ & \\
\cline { 2 - 3 } & 30 & 1.05 & & & \\
\hline \multirow{2}{*}{$\begin{array}{l}\text { VSI, AGA } \\
\text { and SA }\end{array}$} & 33 & 3.5635 & & & & \\
\cline { 2 - 3 } & 18 & 0.5434 & 82.9 & 0.0427 & $62.1 \%$ & $73.2 \%$ \\
\cline { 2 - 3 } & 16 & 0.0012 & & & & \\
\hline
\end{tabular}

The proposed method gave a higher total line loss reduction as compared to PSO method only. However, it gave a lower reduction in total line losses as compared to OPF and IHS. There were no changes in the total line losses and the total voltage deviation when three real power generating RDGs were incorporated compared to when two real power generating RDGs were incorporated. Therefore only two properly sized RDGs can be incorporated to achieve better system performance that would be achieved with three RDGs sized using PSO only or using OPF and IHS. This would save on the cost of setting up the third RDG.

Table 7 shows the optimal RDG sizes, the total line losses and total voltage deviation after incorporating one real and reactive power generating RDG.

Table 7: Results with placement of one RDG generating both real and reactive power

\begin{tabular}{|c|c|c|c|c|c|c|c|}
\hline \multirow{2}{*}{ Method } & \multirow{2}{*}{$\begin{array}{l}\text { Bus } \\
\text { No. }\end{array}$} & \multicolumn{2}{|c|}{ RDG SIZE } & \multirow{2}{*}{$\begin{array}{l}\text { JTLL } \\
\text { (KW) }\end{array}$} & \multirow{2}{*}{ JTVD } & \multirow{2}{*}{$\begin{array}{c}\% \\
\Delta \text { JTLL }\end{array}$} & \multirow{2}{*}{$\begin{array}{c}\% \\
\Delta \text { JTVD }\end{array}$} \\
\hline & & $\begin{array}{c}\mathbf{P} \\
\text { (MW) }\end{array}$ & $\begin{array}{c}\mathbf{Q} \\
\text { (MVAR) }\end{array}$ & & & & \\
\hline PSO [2] & 6 & 2.551 & 1.755 & 68 & $\begin{array}{c}\text { Not } \\
\text { considered }\end{array}$ & $68 \%$ & \\
\hline $\begin{array}{l}\text { OPF and IHS } \\
{[12]}\end{array}$ & 6 & 2.554 & 1.761 & 67.854 & $\begin{array}{c}\text { Not } \\
\text { considered }\end{array}$ & $68 \%$ & \\
\hline $\begin{array}{l}\text { VSI, AGA } \\
\text { and SA }\end{array}$ & 33 & 2.4515 & 1.7568 & 62.2 & 0.0652 & $71.6 \%$ & $59.1 \%$ \\
\hline
\end{tabular}

The proposed method gave a $71.6 \%$ reduction in JTLL in comparison with PSO only and a hybrid of OPF and IHS algorithms which had a $68 \%$ reduction in total line losses. The total voltage deviation was reduced by $59.1 \%$.

The proposed method gave smaller RDG sizes compared to PSO and OPF and IHS methods.

Table 8 shows the optimal RDG sizes, the total line losses and total voltage deviation after incorporating two real and reactive power generating RDGs.

Table 8: Results with placement of two RDGs generating both real and reactive power

\begin{tabular}{|c|c|c|c|c|c|c|c|}
\hline \multirow{2}{*}{ Method } & \multirow{2}{*}{$\begin{array}{l}\text { Bus } \\
\text { No. }\end{array}$} & \multicolumn{2}{|c|}{ DG SIZE } & \multirow{2}{*}{$\begin{array}{l}\text { JTLL } \\
\text { (KW) }\end{array}$} & \multirow{2}{*}{ JTVD } & \multirow{2}{*}{$\% \Delta J T L L$} & \multirow{2}{*}{$\% \Delta J T V D$} \\
\hline & & $\begin{array}{c}\mathbf{P} \\
(\mathbf{M W})\end{array}$ & $\begin{array}{c}\mathbf{Q} \\
\text { (MVAR) }\end{array}$ & & & & \\
\hline \multirow{2}{*}{ PSO [2] } & 6 & 2.551 & 1.755 & \multirow{2}{*}{52} & \multirow{2}{*}{$\begin{array}{c}\text { Not } \\
\text { considered }\end{array}$} & \multirow[b]{2}{*}{$75 \%$} & \\
\hline & 15 & 0.463 & 0.272 & & & & \\
\hline \multirow{2}{*}{$\begin{array}{l}\text { OPF and } \\
\text { IHS [12] }\end{array}$} & 12 & 0.91 & 0.49 & \multirow{2}{*}{29.48} & \multirow{2}{*}{$\begin{array}{c}\text { Not } \\
\text { considered }\end{array}$} & \multirow{2}{*}{$86 \%$} & \\
\hline & 30 & 1.2 & 0.9 & & & & \\
\hline \multirow{2}{*}{$\begin{array}{l}\text { VSI, } \\
\text { AGA and } \\
\text { SA }\end{array}$} & 33 & 2.4515 & 1.7568 & \multirow{2}{*}{53.1} & \multirow{2}{*}{0.0477} & \multirow{2}{*}{$75.7 \%$} & \multirow{2}{*}{$70.1 \%$} \\
\hline & 18 & 0.3912 & 0.2347 & & & & \\
\hline
\end{tabular}

Incorporation of two RDGs generating both real and reactive power using the proposed method gives a $75.7 \%$ reduction in total line losses compared to incorporation of only one RDG which reduced the total line losses by $71.6 \%$. It also gives a better voltage profile by reducing the total voltage deviation by $70.1 \%$ as compared to incorporation of one RDG which reduces the total voltage deviation by $59.1 \%$.

Table 9 shows the optimal RDG sizes, the total line losses and total voltage deviation after incorporating three real and reactive power generating RDGs. 
Table 9: Results with placement of three RDGs generating both real and reactive power

\begin{tabular}{|c|c|c|c|c|c|c|c|}
\hline \multirow{3}{*}{ Method } & \multirow{3}{*}{$\begin{array}{l}\text { Bus } \\
\text { No. }\end{array}$} & \multirow{2}{*}{\multicolumn{2}{|c|}{ DG SIZE }} & \multirow{3}{*}{$\begin{array}{l}\text { JTLL } \\
\text { (KW) }\end{array}$} & \multirow{3}{*}{ JTVD } & \multirow{3}{*}{$\% \Delta J T L L$} & \multirow{3}{*}{$\% \Delta J T V D$} \\
\hline & & & & & & & \\
\hline & & $\begin{array}{c}\mathbf{P} \\
(\mathbf{M W})\end{array}$ & $\begin{array}{c}\mathbf{Q} \\
\text { (MVAR) }\end{array}$ & & & & \\
\hline \multirow{3}{*}{ PSO [2] } & 6 & 2.551 & 1.755 & \multirow{3}{*}{43} & \multirow{3}{*}{$\begin{array}{c}\text { Not } \\
\text { considered }\end{array}$} & \multirow{3}{*}{$80 \%$} & \\
\hline & 15 & 0.463 & 0.272 & & & & \\
\hline & 25 & 0.685 & 0.31 & & & & \\
\hline \multirow{3}{*}{$\begin{array}{l}\text { OPF and } \\
\text { IHS [12] }\end{array}$} & 13 & 0.78 & 0.42 & \multirow{3}{*}{13.47} & \multirow{3}{*}{$\begin{array}{c}\text { Not } \\
\text { considered }\end{array}$} & \multirow{3}{*}{$94 \%$} & \\
\hline & 25 & 0.83 & 0.43 & & & & \\
\hline & 30 & 1.15 & 0.86 & & & & \\
\hline \multirow{3}{*}{$\begin{array}{l}\text { VSI, AGA } \\
\text { and SA }\end{array}$} & 33 & 2.4515 & 1.7568 & \multirow{3}{*}{53} & \multirow{3}{*}{0.0652} & \multirow{3}{*}{$75.8 \%$} & \multirow{3}{*}{$59.1 \%$} \\
\hline & 18 & 0.3912 & 0.2347 & & & & \\
\hline & 32 & 0 & 0.0092 & & & & \\
\hline
\end{tabular}

Incorporation of a third real and reactive power generating RDG did not have any considerable effect on the reduction of line losses compared to the system with two such RDGs integrated. However, the voltage profile deteriorated from a $70.1 \%$ reduction in total voltage deviation with two RDGs to $59.1 \%$ reduction with three RDGs. The results in table 7 and 8 indicate that the system achieves enhanced performance with only two RDGs incorporated. Integration of a third RDG would result to increased costs of setting up the third RDG unit which would cause a distortion of the system's performance. Therefore the proposed method would be used in optimally siting ad sizing two RDG units.

\section{CONCLUSION}

This paper has presented a three method approach of solving the multi-objective problem of reducing total line losses and total voltage deviation in IEEE 33 bus system. The optimal locations were obtained using Voltage Stability Index and a hybrid of Adaptive Genetic Algorithm and Simulated Annealing was used to achieve the optimal RDG sizes while solving both objectives simultaneously because it has the better convergence. Results show that having one and two optimally placed and sized RDGs would improve the system performance. A third RDG would not be required with the propose algorithm because it would distort the system performance. Further work can be done on applying this method on larger interconnected test systems and also tested on a network with a variable loading profile.

\section{REFERENCES}

[1] Miroslav Begovic et al, "Integration of Photovoltaic Distributed Generation in the Power Distribution Grid," in 45th International Conference on System Sciences, Hawaii, 2012.
[2] K. Varesi, "Optimal Allocation of DG Units for Power Loss Reduction and Voltage Profile Improvement of Distribution Networks using PSO Algorithm," in International scholarly and Scientific Research and Innovation, 2011

[3] A. S. Telang and P. P. B. , "Application of Voltage Stability Indices for Proper Placement of STATCOM under Load Increase Scenerio," International Journal of Energy and Power Engineering, vol. 10, no. 7 , 2016

[4] U. Eminoglu, "A voltage Stability Index for Radial Distribution Networks," in 42nd International Universities Power Engineering Conference, Turkey, 2007.

[5] Naveena. Jain et al, "Planning and Impact Evaluation of Distributed Generators in Indian Context using Multi-Objective Particle Swarm Optimization".

[6] Pradeepa. H et al, "Optimal Allocation of Combined DG and Capacitor Units for Voltage Stability Enhancement," Smart Grid Technologies, August 6-8 2015.

[7] K. Rayudu et al, "Voltage Stability Enhancement Based on Particle Swarm Optimization and LP Technique," International conference of EmergingTechnological Trends, 2016.

[8] Mengqi. Yao et al, "Using Demand Response to Improve Power System Voltage Stability Margins".

[9] Manijeh Alipour et al, "Enhancement of Power System Voltage Stability Using New Centralized Adaptive Load Shedding Method," 30th Power System Conference (PCS2015), pp. 23-25, November 2015.

[10] Gogu Rajendar et al, "Improvement of Voltage Stability by Optimal Capacitor Placement Using Sensitivity Matrix," International conference on Signal Processing, Communication, Power and Embedded System (SCOPES), 2016.

[11] Satish Kansal et al. , "Optimal placement of distributed generation in distribution networks," International Journal of Engineering, Science and Technology, vol. 3, pp. 47-55, 2011.

[12] Sandeep Kaur et al. , "Harmony Search and OPF Based Hybrid Approach for Optimal Placement of Multiple DG Units".

[13] F. Mahmood et al, "Weakest Location Exploration in IEEE 14 Bus System for Voltage Stability Improvement Using STATCOM, Synchronous Condenser and Static Capacitor," International Conference on Electrical, Computer and Communication Engineering (ECCE), pp. 16-18, February 2017. 